Diabetologia (1994) 37: 365-371

\title{
Slow metabolic deterioration towards diabetes in islet cell antibody positive patients with autoimmune polyendocrine disease
}

\author{
R. Wagner ${ }^{1}$, S. Genovese ${ }^{1,2}$, E. Bosi ${ }^{2}$, F. Becker ${ }^{1}$, P.J. Bingley ${ }^{3}$, E. Bonifacio ${ }^{1}$, K. A. Miles ${ }^{1}$, M. R.Christie ${ }^{4}$, \\ G.F. Bottazzo , E.A.M. Gale \\ ${ }_{1}^{1}$ Department of Immunology, The London Hospital Medical College, London, UK \\ 2 Department of Medicine, San Raffaele Hospital Scientific Institute, Milan, Italy \\ ${ }^{3}$ Department of Diabetes and Metabolism, St. Bartholomew's Hospital, London, UK \\ ${ }^{4}$ Nuffield Department of Clinical Biochemistry, John Radcliffe Hospital, Oxford, UK
}

\begin{abstract}
Summary We studied metabolic progression to IDDM in a cohort of adults who are ICA-positive and have associated autoimmune endocrine disease or circulating organ-specific autoantibodies (the Polyendocrine Study). Of the 186 individuals recruited 27 developed overt diabetes after a median follow-up of 4.5 years (range 0.4-12). Of these, eight patients did not require insulin treatment until at least 6 months after clinical diagnosis, with an interval of 1.8 years $(1.2-5.7)$. An IVGTT was performed in 38 subjects and 23 had sequential studies. Of the initial 38 subjects six developed diabetes and only three showed a loss of FPIR to glucose (below the first percentile of a normal control group) before clinical onset of the disease. An additional three subjects showed a loss of the FPIR, and all still have normal glucose tolerance after median follow-up of 28 months (22-95). A "whole" or "mixed" pattern of islet cell staining was found in five of the six patients who developed diabetes and antibodies
\end{abstract}

against an islet $37 \mathrm{k}$-antigen were detectable in four patients, all of whom required insulin soon after diagnosis. A beta-cell "selective" ICA staining pattern was seen in 14 of 17 subjects who did not develop diabetes and the "mixed" pattern in only three. None of this group had detectable $37 \mathrm{k}$-antibodies. We conclude that metabolic deterioration is slow in polyendocrine patients, and that the IVGTT has less prognostic significance in this group than in first degree relatives of patients with IDDM. In contrast, the presence of the "whole" or "mixed" ICA staining pattern or of $37 \mathrm{k}$ antibodies can identify a high risk of progression to IDDM within this polyendocrine population and may indicate the rate of metabolic deterioration. [Diabetologia (1994) 37: 365-371]

Key words Intravenous glucose tolerance test, $37 \mathrm{k}$ antibodies, islet cell antibody staining pattern, polyendocrinopathy.
Islet-cell antibodies (ICA) are the most widely used serological markers of risk of progression to IDDM [1]. Additional markers include insulin autoantibodies [2] and antibodies against a $64 \mathrm{kD}$ islet-protein, recently

Received: 14 June 1993

and in revised form: 18 October 1993

Corresponding author: Professor E. A. M. Gale, Department of Diabetes and Metabolism, St. Bartholomew's Hospital, London EC1 A 7 BE, UK

Abbrevations: IDDM, Insulin-dependent diabetes mellitus; ICA, islet cell antibodies; IVGTT, intravenous glucose tolerance test; FPIR, first phase insulin response; OGTT, oral glucose tolerance test; GAD, glutamic acid decarboxylase; JDF, Juvenile Diabetes Foundation. identified as the gamma amino butyric acid synthesizing enzyme, GAD [3, 4]. Loss of the FPIR to i. v. glucose [5] also provides a highly specific marker of risk in family studies [6] especially in the presence of high titre ICA and insulin autoantibodies [7].

While the value of these predictive markers is well established in first degree relatives, their role in other high risk populations is less clear. We have identified a distinct group of ICA-positive individuals, mainly adult and predominantly female, with associated organ-specific autoimmune disease or autoantibodies, the majority of whom do not progress to IDDM after long follow-up despite having high levels of ICA [8]. Within this population it has been possible to identify distinct specificities of ICA [9], and to show that all patients with the conventional "whole islet" ICA staining pat- 
tern developed IDDM while the individuals who preferentially show the "selective" pattern of islet staining remain disease free. Other recently described antibodies against $37 / 40 \mathrm{kDa}$ tryptic fragments of a $64 \mathrm{kDa}$ islet-protein (37k-antigen) that is distinct from GAD $[10,11]$ are markers of rapid progression to IDDM in this population [12]. We now report our experience of metabolic abnormalities preceding insulin dependence in this group and relate these to ICA specificity and to other autoantibodies.

\section{Patients and methods}

\section{Patients}

The Polyendocrine Study was established in 1984. Inclusion criteria were ICA positivity on at least two occasions, absence of diabetes and the presence of at least one other organ-specific autoimmune manifestation (organ-specific autoantibodies and/ or clinical organ-specific autoimmune disease). The subjects and methods have been reported previously in detail [8]. Patients were ascertained by screening for ICA in all serum samples sent to our autoimmune serology laboratory for any reason. Progression to diabetes was evaluated retrospectively from 1976-1984 and prospectively from 1984 . To date, 253 ICA-positive individuals have been identified. The study includes 186 subjects of whom 27 developed IDDM, 24 died without developing overt insulin requiring diabetes, 24 were lost to follow-up and 111 remain non-insulin-dependent (Fig. 1).

Metabolic studies. By April 1992, 38 of these individuals had been tested with an IVGTT, and 23 had sequential investigations (range 2-8). The median age at first testing was 41 years (range 16-69). The median follow-up period from the first IVGTT was 2.9 years (1.2-7.9). Three additional patients, aged 26,74 and 77 years had $1-3$ oral glucose tolerance tests without IVGTT. Thirty-one patients were female and 10 male. All were non-obese, and were biochemically euthyroid at the time of study.

Diabetes was diagnosed according to World Health Organization criteria, and information concerning initiation of insulin therapy was obtained from the clinical records or from a detailed questionnaire sent to the physician who was caring for the patient. Details recorded included date of first insulin injection, presenting symptoms and presence or absence of ketonuria. All procedures used were approved by our local Research Ethics Committee and all subjects gave informed consent.

Control subjects. Fifty one ICA-negative subjects with no family history of diabetes served as controls. The median age was 29 years (18-48), and 30 men and 21 women were studied. All had a normal body mass index.

\section{Methods}

Intravenous glucose tolerance tests. All subjects undergoing metabolic testing were instructed to follow a non-carbohydrate restricted diet for 3 days preceding each test. After an overnight fast, both antecubital veins were cannulated under local anaesthesia. Subjects rested for $30 \mathrm{~min}$ and baseline samples were taken 10 and $5 \mathrm{~min}$ before the glucose infusion. Glucose $(25 \mathrm{~g}$ ) was given as a $50 \%$ solution infused at a rate of $20 \mathrm{~g} / \mathrm{min}$. The

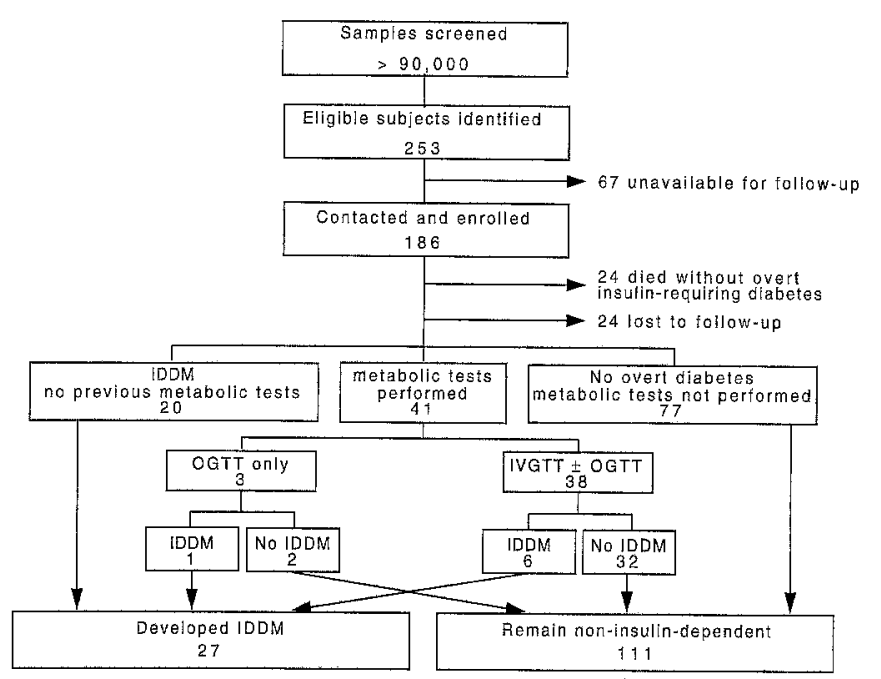

Fig.1. The Polyendocrine Study Cohort

point midway through the infusion was taken as time zero. Samples were taken at 1,3, 5, 7, 10 and $20,30,45$ and $60 \mathrm{~min}$ in $22 \mathrm{pa}$ tients and at 1,3,5, and $10 \mathrm{~min}$ in the remainder.

Oral glucose tolerance tests. Glucose monohydrate $75 \mathrm{~g}$ was dissolved in $300 \mathrm{ml}$ of water and administered over $1 \mathrm{~min}$. Sampling took place $5 \mathrm{~min}$ before and $30,60,90$ and $120 \mathrm{~min}$ after glucose was administered.

\section{Assays}

Islet cell antibodies. ICA were detected by indirect immunofluorescence using $25 \mu \mathrm{m}$ cryostat sections of blood group 0 human pancreas and $25 \mu \mathrm{l}$ of undiluted serum [13]. ICA were initially scored by intensity as negative, weakly positive $(w+)$, positive $(+)$, or strongly positive $(++)$. After the recommendation of the 2 nd International Workshop on the standardization of cytoplasmic ICA, quantification in JDF units was performed in the first and follow-up samples (when available) in 35 of the subjects who had IVGTTs using serial dilutions of serum in $10 \mathrm{mmol} / 1$ phosphate buffered saline (PBS) pH 7.2 in parallel with standard samples of $4,8,16,32$, and 80 JDF units ICA [14]. The assay has a lower limit of detection of 4 JDF units.

Distinct islet-cell immunofluorescence pattern. The technique used to determine the pattern of islet staining has been reported elsewhere [9]. Briefly, for the four layer immunofluorescent technique, sections were incubated with undiluted patient sera, then washed in PBS and incubated with fluorescein isothiocyanate-rabbit anti-human IgG (Dako, Glostrup, Denmark). The second layer consisted of an incubation with either monoclonal antibodies to human glucagon (GLU-1-F120; Novo, Copenhagen, Denmark) or monoclonal antibody to porcine proinsulin (PPI-2-F12; Novo). The sections were washed again in PBS and incubated with biotinylated horse anti-mouse immunoglobulin (Vector Laboratories Inc, Burlingame, Calif., USA). After further washing in PBS, the anti-hormone antibodies were visualised by incubation of sections with tetramethyl rhodamine isothiocyanate-avidin D (Vector Laboratories Inc). 
Table 1. Insulin autoantibodies, ICA staining pattern and antibodies against GAD, $50 \mathrm{k}$ and $37 / 40 \mathrm{k}$ islet antigens in patients grouped according to their IVGTT

\begin{tabular}{|c|c|c|c|c|c|c|c|c|c|c|}
\hline \multirow{2}{*}{$\begin{array}{l}\text { Patient } \\
\text { (sex) }\end{array}$} & \multirow{2}{*}{\multicolumn{2}{|c|}{$\begin{array}{l}\text { Age at 1st FPIR } \\
\text { IVGTT } \\
\text { (years) }\end{array}$}} & \multirow{2}{*}{$\begin{array}{l}\text { Insulin auto- } \\
\text { antibodies } \\
(\mathrm{nU} / \mathrm{ml})\end{array}$} & \multicolumn{5}{|c|}{ ICA specificities } & \multirow[t]{2}{*}{ IDDM } & \multirow{2}{*}{$\begin{array}{l}\text { Follow-up after } \\
\text { 1st IVGTT } \\
\text { (months) }\end{array}$} \\
\hline & & & & JDF units & Pattern & GAD & $50 \mathrm{k}$ & $37 / 40 \mathrm{k}$ & & \\
\hline \multicolumn{11}{|l|}{ Group 1} \\
\hline $\mathrm{DC}(\mathrm{F})$ & 39 & $<1$ st percentile & 17 & $>80$ & $\mathrm{~m}$ & ++ & + & - & - & 95 \\
\hline $\mathrm{AB}(\mathrm{M})$ & 24 & $<1$ st percentile & 12 & 14 & $\beta$ & + & + & - & - & 28 \\
\hline $\mathrm{RM}(\mathrm{F})$ & 39 & $<1$ st percentile & -4 & 69 & NT & + & + & - & - & 22 \\
\hline $\mathrm{DG}(\mathrm{F})$ & 42 & $<$ 1st percentile & NT & 35 & $\mathrm{~m}$ & + & + & - & + & 46 \\
\hline $\mathrm{CW}(\mathrm{F})$ & 47 & $<1$ st percentile & 16 & 49 & $\mathrm{w}$ & ++ & ++ & + & + & 34 \\
\hline $\operatorname{MR}(\mathrm{F})$ & 49 & $<1$ st percentile & 122 & $>80$ & NT & + & + & - & + & 82 \\
\hline \multicolumn{11}{|l|}{ Group 2} \\
\hline $\mathrm{NE}(\hat{\mathrm{F}})$ & 21 & normal & 77 & 30 & w & ++ & ++ & + & + & 23 \\
\hline $\mathrm{MG}(\mathrm{M})$ & 16 & normal & 77 & 52 & $\mathrm{w}$ & + & + & + & + & 21 \\
\hline $\mathrm{BE}(\mathrm{M})$ & 52 & normal & 140 & $>80$ & $\mathrm{~m}$ & + & + & + & + & 84 \\
\hline \multicolumn{11}{|l|}{ Group 3} \\
\hline $\mathrm{JA}(\mathrm{M})$ & 54 & normal & 7 & $>80$ & $\beta$ & + & + & - & - & 82 \\
\hline $\operatorname{LD}(\mathrm{F})$ & 18 & normal & 36 & $>80$ & $\mathrm{~m}$ & NT & $\mathrm{NT}$ & - & - & 77 \\
\hline $\mathrm{AD}(\mathrm{M})$ & 24 & normal & -1 & 11 & NT & + & + & - & - & 59 \\
\hline $\mathrm{AD}(\mathrm{F})$ & 44 & normal & 44 & $>80$ & $\beta$ & + & + & - & - & 79 \\
\hline $\mathrm{SF}(\mathrm{F})$ & 16 & normal & -9 & $>80$ & $\beta$ & + & + & - & - & 80 \\
\hline $\mathrm{AG}(\mathrm{M})$ & 56 & normal & -5 & 80 & $\mathrm{~m}$ & + & + & - & - & 78 \\
\hline $\mathrm{LW}(\mathrm{F})$ & 28 & normal & 76 & $>80$ & $\beta$ & + & + & - & - & 78 \\
\hline $\mathrm{AK}(\mathrm{F})$ & 52 & normal & 20 & $>80$ & $\beta$ & + & + & - & - & 31 \\
\hline $\mathrm{SM}(\mathrm{F})$ & 50 & normal & 3 & $>80$ & $\beta$ & + & + & - & - & 82 \\
\hline $\mathrm{DP}(\mathrm{F})$ & 47 & normal & NT & 45 & $\beta$ & $\mathrm{NT}$ & $\mathrm{NT}$ & - & - & 30 \\
\hline $\mathrm{CD}(\mathrm{F})$ & 30 & normal & 8 & $>80$ & $\beta$ & + & + & - & - & 30 \\
\hline $\mathrm{MM}(\mathrm{F})$ & 42 & normal & -6 & 6 & $\beta$ & - & - & - & - & 29 \\
\hline $\mathrm{RS}(\mathrm{F})$ & 53 & normal & NT & 28 & $\mathrm{NT}$ & - & - & - & - & 29 \\
\hline CR (F) & 41 & normal & 1 & $>80$ & $\beta$ & $\mathrm{NT}$ & NT & - & - & 29 \\
\hline $\mathrm{SG}(\mathrm{F})$ & 37 & normal & -2 & 80 & $\beta$ & $\mathrm{NT}$ & NT & - & - & 28 \\
\hline $\mathrm{JC}(\mathrm{F})$ & 69 & normal & 30 & $>80$ & $\beta$ & NT & NT & - & - & 22 \\
\hline $\mathrm{DR}(\mathrm{F})$ & 37 & normal & 1 & $>80$ & $\mathrm{~m}$ & + & + & - & - & 23 \\
\hline $\mathrm{PR}(\mathrm{F})$ & 25 & normal & 11 & 18 & NT & + & + & - & - & 23 \\
\hline $\mathrm{RM}(\mathrm{F})$ & 39 & normal & -4 & 69 & $\mathrm{NT}$ & + & + & - & - & 22 \\
\hline WC (M) & 60 & normal & 210 & 13 & $\beta$ & $\mathrm{NT}$ & NT & - & - & 13 \\
\hline
\end{tabular}

Group 1, patients with abnormal IVGTT; group 2, patients with normal IVGTT who progressed to insulin-treated diabetes; group 3, patients with normal IVGTT who remained non- diabetic throughout follow-up. m, Mixed ICA pattern; w, whole ICA pattern $\beta$, beta-cell selective ICA pattern; NT, not tested
Antibodies against $G A D$ and tryptic fragments of islet $64 \mathrm{kDa}$ antigens. Immunoprecipitating antibodies to GAD were measured by determining the enzyme activity immunoprecipitated by antibodies in sera from a soluble extract of rat brain as previously described [15]. Sera were regarded as positive for anti-GAD antibodies if the relative antibody activity exceeded 2 SD of the activity in sera from a group of 30 healthy control individuals (mean $\pm \mathrm{SD} ; 6.2 \pm 3.4 \%$ of positive control). Using this assay antibodies to GAD were found in $64 \%$ of newly-diagnosed patients with IDDM and $4 \%$ of control subjects [15]. Antibodies to $50 \mathrm{kDa}$ tryptic fragments of GAD and $40 \mathrm{kDa}$ and $37 \mathrm{kDa}$ fragments of $37 \mathrm{k}$-antigen were measured by immunoprecipitation of $\left[{ }^{35} \mathrm{~S}\right]$ methionine-labelled polypeptides released from particulate fractions of neonatal rat islets by trypsin treatment as previously described [10]. Serum samples were regarded as positive for antibodies to tryptic fragments of islet $64 \mathrm{k}$ antigens if a band corresponding to the appropriate polypeptide could be detected on the autoradiogram. Using this assay anti$37 \mathrm{k}$ antibodies have been found in $78 \%$ of patients with newlydiagnosed diabetes and none of more than 200 control subjects tested to date $[10]$
Insulin autoantibodies. These were measured in the laboratory of Dr A.Ziegler, Munich, Germany, by a competitive radioimmunoassay as previously described [2]. Positivity to insulin autoantibodies was defined as more than $4 \mathrm{SD}$ above the normal population mean ( $\geq 49 \mathrm{nU} / \mathrm{ml}$ ). Serum samples were available from 29 patients investigated by means of IVGTT and all 29 were used for determination of antibodies against $37 / 40 \mathrm{kDa}$ fragments, 26 for insulin autoantibodies and 23 for antibodies against GAD and $50 \mathrm{kDa}$ fragments. Of the 29 samples 23 were also used for ICA staining studies.

Other organ-specific antibodies. Gastric parietal cell and adrenal antibodies were tested in all samples by immunofluorescence on 4- $\mu \mathrm{m}$ cryostat sections of fresh frozen human blood group 0 organ tissues, and steroid producing cell antibodies on cryostat sections of unfixed rat ovary and testis [16]. Thyroglobulin and thyroid microsomal antibodies were measured by haemagglutination with commercial kits (Wellcome, Dartford, UK). Titres of more than $1 / 20$ for thyroglobulin antibodies and more than $1 / 400$ for thyroid microsomal antibodies were considered positive. For all antibodies, sera were either tested fresh or after storage at $-20^{\circ} \mathrm{C}$. 


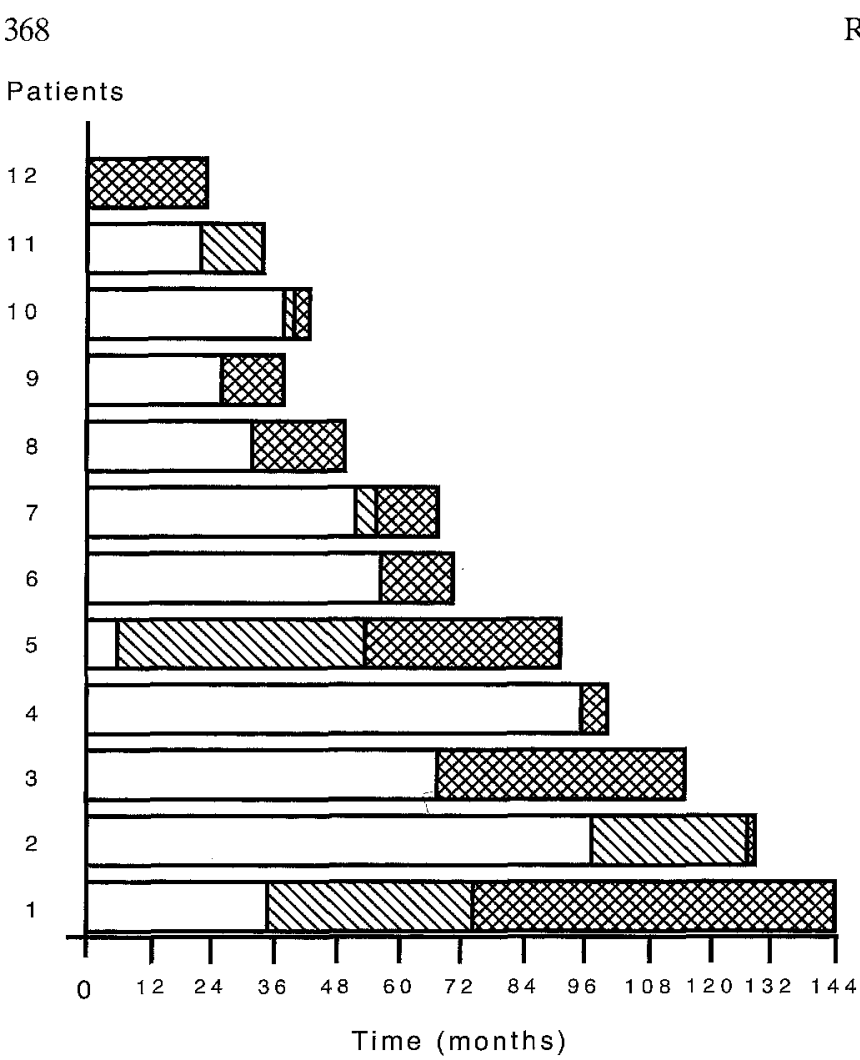

Fig. 2. Duration of metabolic abnormalities in 12 of the 27 patients who had a slow rate of metabolic deterioration before insulin-requiring diabetes. $\square$, ICA-positivity, $\$$ impaired glucose tolerance, non-insulin-requiring diabetes

Blood glucose. Samples for glucose analysis were collected into fluoride tubes and assayed within $4 \mathrm{~h}$. Whole blood glucose was determined by a glucose oxidase method using a YSI model 23 AM glucose analyzer (Yellow Springs Instrument Co., Yellow Springs, Ohio, USA). The inter-assay coefficient of variation was $5.5 \%$ at $2.2 \mathrm{mmol} / \mathrm{l}$ and $2.7 \%$ at $11.6 \mathrm{mmol} / \mathrm{l}$.

Insulin. Blood was taken into tubes coated with heparin and containing aprotinin (Trasylol, Bayer, Newbury, UK) at a concentration of 500,000 kallikrein inactivator units $/ 50 \mathrm{ml}$. Samples were centrifuged immediately at $4^{\circ} \mathrm{C}$, the plasma was then frozen and stored at $-20^{\circ} \mathrm{C}$ until analysis. Immunoreactive insulin was determined using a double antibody radioimmunoassay using a guinea pig anti-bovine insulin antiserum (Immunodiagnostic Systems Ltd, Washington, Tyne and Wear, UK) as the first antibody and sheep anti-guinea pig Fc (International Laboratory Services, London, UK) as the separating antibody. The intraassay coefficient of variation was $6.6 \%, 7.4 \%$ and $5.9 \%$ at concentrations of $4.7,34.8$ and $77.9 \mathrm{mU} / \mathrm{l}$ respectively, and interassay variation was $4.6,5.1$ and $3.7 \%$ at the same insulin concentrations.

\section{Statistical analysis}

Results are given as median (range). The FPIR to i.v. glucose was calculated as the incremental $0-10 \mathrm{~min}$ area under the insulin curve. Results were log-transformed before calculation of percentiles because of a non-normal distribution in the control group. For purposes of this analysis, the first test in which the FPIR was below the 1 st percentile of the control group was used to define length of follow-up. Life-table analysis and log-rank
R. Wagner et al.: Metabolic changes in ICA + polyendocrine patients

testing were used to compare the cumulative risk of IDDM in patients with insulin responses to glucose infusion above and below the 1 st percentile.

\section{Results}

\section{Slow metabolic decompensation}

Over the observation period of up to 16 years, 27 of 186 patients have progressed to insulin-dependent diabetes. Although the age distribution was wide, most of the patients were adults with a median age of 50 years (17-79); 19 of the 27 were female. Both sex and age corresponded to the overall distribution in the cohort [8]. Two patients were overweight, but the remainder had a normal body mass index. Two patients died with impaired oral glucose tolerance and one with noninsulin-requiring diabetes. Six patients had IVGTTs prior to diagnosis of IDDM, and these are presented in Table 1.

Of the 27 patients who developed IDDM 12 progressed through a stage of impaired glucose tolerance or non-insulin-requiring diabetes before starting insulin therapy. The duration of these changes is shown in Figure 2. The median intervals were 21 months (1-42) for those with impaired glucose tolerance, and 19 months (2-69) for those with non-insulin-requiring diabetes. All patients in the latter category were treated with oral hypoglycaemic drugs before insulin was required.

\section{Insulin response to $i$. v. glucose}

Results from those who had at least one abnormal IVGTT and/or developed diabetes subsequently are presented in Table 1 . To date, three of six $(50 \%)$ patients with FPIR below the 1 st percentile have progressed to IDDM 34, 46, and 82 months after the first IVGTT. Another patient $(\mathrm{AB})$ had a normal FPIR in the following 3 IVGTTs and two are still non-diabetic and have normal glucose tolerance 22 and 95 months after the first IVGTT. Three of the $32(9 \%)$ patients with normal FPIR developed overt diabetes 12,13 and 23 months after the last IVGTT.

\section{Glucose tolerance in patients who underwent IVGTTS}

We performed oral glucose tolerance tests in five patients with impaired insulin responses to i.v. glucose. One was found to have impaired glucose tolerance 3 months after the first IVGTT, developed non-insulinrequiring diabetes after 41 months and started insulin after 82 months (patient MR). Another was found to have impaired glucose tolerance 1 month after the IVGTT was performed, developed non-insulin-requiring diabetes 31 months later and 2 months thereafter 
required insulin (patient $\mathrm{CW}$ ). Oral glucose tolerance has remained normal in the other three patients. Nine additional patients have had normal glucose tolerance following normal IVGTTs.

\section{Predictive value of reduced FPIR to i. v. glucose}

The incidence of diabetes for those with a FPIR below the 1 st percentile was 0.14 per patient/year of followup as against 0.026 per patient/year for those with a response above the 1 st percentile. By life-table analysis, the cumulative risk of IDDM within 7 years was $50 \%$ in those with loss of FPIR compared with $20 \%$ in those with normal FPIR. Log-rank testing showed that patients with an abnormal IVGTT had a significantly higher rate of progression to IDDM than those with normal IVGTT $(p<0.05)$.

ICA pattern and antibodies against $G A D, 50 \mathrm{kDa}$ and $37 / 40 \mathrm{kDa}$ tryptic fragments of islet $64 \mathrm{kDa}$ antigens in patients who underwent IVGTT

The results of analyses of antibodies to GAD, tryptic fragments of $64 \mathrm{kDa}$ islet antigen and ICA staining pattern in patients who had IVGTT are presented in Table 1. Patients were divided into three groups. Group 1 included patients with abolished FPIR, group 2 those who progressed to insulin-treated diabetes despite normal FPIR, and group 3 those with normal FPIR who have not developed diabetes to date. Of the 23 individuals tested 21 were positive for antibodies to GAD and $50 \mathrm{kDa}$ fragments. The two individuals without these antibodies had ICA 6 and 28 JDF units respectively. Antibodies against a $37 / 40 \mathrm{kDa}$ tryptic fragments of islet antigen (37k-antibodies) were detected in four of the six patients who developed diabetes and in none of those with normal FPIR who did not develop diabetes. All four required insulin treatment and apparently had an acute onset of symptoms. One of them had impaired glucose tolerance 31 months before developing diabetes but required insulin within 2 months of diagnosis. One of the two patients without $37 \mathrm{k}$-antibodies developed non-insulinrequiring diabetes before IDDM and the other developed acute clinical symptoms almost 4 years after the abnormal IVGTT.

The ICA staining pattern was determined in 23 patients tested by IVGTT. The ICA "whole islet" staining pattern was only detected in three of the four patients who were $37 \mathrm{k}$-antibody positive whereas all the others, had a "mixed" or "beta-cell selective" pattern. Thus, the combination of $37 \mathrm{k}$-antibody positivity and the "whole islet" staining pattern of islets was very highly predictive of IDDM in this population.

\section{Insulin autoantibody measurement}

Insulin autoantibodies were determined in 26 of the patients who had IVGTTs and were tested for $37 \mathrm{k}$ antibodies and 21 of them were also tested for antibodies to GAD and $50 \mathrm{kDa}$ fragments. As shown in Table 1, four of the six positive patients developed IDDM.

\section{Discussion}

The Polyendocrine Study was undertaken to study the natural history of progression to IDDM in ICA-positive patients with multiple organ-specific autoimmune disease. It has shown that, in comparison with ICApositive first degree relatives of children with IDDM [1], ICA-positive polyendocrine patients are less likely to develop diabetes over a given period of time [8]. Thus, of 186 patients involved in the study, only 27 have developed IDDM over an observation period of up to 16 years. More precisely, $62 \%$ of the patients with ICA of $80 \mathrm{JDF}$ units or more did not have diabetes after 10 years [8]. As might be expected from this observation, our experience has been that metabolic deterioration develops slowly, so that at least 12 of 27 patients showed a period of impaired glucose tolerance or a period of non-insulin-dependent diabetes before requiring insulin. Eight had diabetes by World Health Organization criteria for a minimum of 6 and maximum of 69 months before requiring insulin. All of these had a normal body mass index. The IVGTT study has shown that despite high ICA levels, 32 of 38 patients investigated had a normal FPIR to i.v. glucose, and none of these showed deterioration over a follow-up period of up to 82 months. Fourteen of the patients with repeated IVGTTs have persistently high ICA titres (more than 80 JDF units) yet retain a normal FPIR to glucose after a median follow-up period of 6.3 (1-12) years after first detection of ICA. Even when the first phase response was lost, diabetes developed slowly, if at all. Thus, three patients developed diabetes 34, 46 and 82 months after the FPIR was found to be abolished, whereas two of the patients with abnormal IVGTTs have normal glucose tolerance 22 and 95 months later, despite ICA titres of 69 and more than $80 \mathrm{JDF}$ units.

Two patients (patient CW and MR) showed a complete sequence of metabolic changes, with abolished FPIR, impaired glucose tolerance, non-insulin-requiring diabetes and finally IDDM. The fact that the IVGTT discriminated relatively poorly between patients who went on to require insulin and those who did not, suggests that it is less predictive of progression to diabetes in polyendocrine patients than in younger familial cases of IDDM. It is however striking that our two youngest patients (aged 16 and 17 at first IVGTT) developed IDDM 23 and 13 months, respectively after 
IVGTTs showing insulin secretion within the normal range, emphasising likely heterogeneity in the rate of progression to diabetes. A probable interpretation is that younger patients progress faster to diabetes, and that secretory abnormalities will be missed if the interval between IVGTTs is too long [5]. At present we cannot be sure if the differences we have observed between familial and polyendocrine patients are due to age (familial cases are younger) or to heterogeneity in the disease process itself; this question could only be resolved by pooling a large series of ICA-positive polyendocrine patients with age- and sex-matched ICApositive first degree relatives.

Our data imply that despite high ICA titres and low FPIR, some of our polyendocrine patients might never develop diabetes. We have found two distinct staining patterns of ICA identified by a four layer immunofluorescence technique, one staining the whole islet and the other partially beta-cell selective. The latter seems characteristic of those polyendocrine patients who have not developed diabetes over a long period of time despite high ICA titres, and the former, of those who will develop IDDM [9]. Moreover, distinct antibodies with specificities to $50 \mathrm{kDa}$ and $37 / 40 \mathrm{kDa}$ proteolytic fragments of islet $64 \mathrm{kDa}$ antigens have recently been identified [10,11]. We have shown that antibodies against brain GAD or $50 \mathrm{kDa}$ fragment of islet GAD were detectable in almost all polyendocrine patients, whether or not they develop IDDM, whereas $37 \mathrm{k}$-antibodies were associated with acute onset of IDDM [12]. In this study, antibodies against the islet tryptic $37 \mathrm{kDa}$ fragment were present in four of the five patients who had an acute onset of IDDM, starting insulin soon after diagnosis, but not in the patient with long period of non-insulin-requiring diabetes before insulin dependence. These antibodies were detectable in all three patients who did not have IVGTT abnormalities before insulin-treated diabetes. In the only patient who developed acute onset of insulin-treated diabetes despite $37 \mathrm{k}$-antibody negativity and who had the "mixed" ICA pattern (patient DG), the determination had been made nearly 4 years before overt diabetes and might have changed closer to the time of diagnosis of diabetes. A longitudinal determination of those antibody specificities will be required to clarify this possibility. All the remaining patients with normal IVGTT who have not yet developed diabetes were $37 \mathrm{k}$-antibody negative and did not show the "whole" islet ICA pattern. Detection of these antibody specificities might therefore permit us to select a population at high risk for developing diabetes in whom frequent metabolic testing is indicated despite a normal initial insulin response to the IVGTT.

In conclusion, we have identified a cohort of ICApositive adult patients with polyendocrine disease, and metabolic studies have confirmed that their progression to diabetes is very slow. The group of patients is heterogeneous, and the relative influence of age or other autoimmune disease upon the rate of progression to diabetes remains unclear. Application of the novel antibody specificities presented here might also explain these differences in the rate of progression to insulin-treated diabetes. Most similar studies have been performed in children, and adult patients included in such studies have not been fully characterized in terms of other organ-specific autoimmunity and family history of organ-specific endocrine diseases [17]. Only prospective studies with a large number of patients and comparable standardized tests [18] will enable questions such as these to be resolved.

Acknowledgements. The work was supported by the Juvenile Diabetes Foundation, the Research Advisory Committee of The Royal London Hospital Special Trustees and the Joint Research Board of St. Bartholomew's Hospital. R. Wagner was supported by a travelling Fellowship from Hoechst-Germany and the B.Braun-Stiftung, Melsungen, Germany, and S. Genovese by a Fellowship from the Istituto Scientifico San Raffaele, Milan, Italy. E. Bonifacio received a Research Fellowship from the Juvenile Diabetes Foundation and M. R. Christie is a Royal Society University Research Fellow. We thank Dr. A.Ziegler for the determination of insulin autoantibodies.

\section{References}

1. Tarn AC, Thomas JM, Dean BM et al. (1988) Predicting insulin-dependent diabetes. Lancet I: $845-850$

2. Ziegler AG, Ziegler R, Vardi P, Jackson R, Soeldner S, Eisenbarth G (1989) Life-table analysis of progression to diabetes of anti-insulin autoantibody-positive relatives of individuals with Type 1 diabetes. Diabetes 38: 1320-1325

3. Atkinson MA, Maclaren NK, Scharp DW, Lacy PE, Riley WJ (1990) 64,000 $\mathrm{M}_{\mathrm{r}}$ autoantibodies as predictors of insulindependent diabetes. Lancet 335: 1357-1360

4. Bækkeskov S, Nielsen JH, Marner B, Bilde T, Ludvigsson J, Lernmark $\AA$ (1982) Antibodies in newly diagnosed diabetic children immunoprecipitate human pancreatic islet cell proteins. Nature 298: 167-169

5. Srikanta S, Ganda OP, Eisenbarth GS, Soeldner JS (1983) Islet cell antibodies and beta-cell function in monozygotic triplets and twins initially discordant for type 1 diabetes mellitus. N Engl J Med 308: 322-325

6. Bleich D, Jackson RA, Soeldner JS, Eisenbarth GS (1990) Analysis of metabolic progression to type 1 diabetes in $\mathrm{ICA}+$ relatives of patients with type 1 diabetes. Diabetes Care 13: 111-118

7. Jackson RA, Soeldner JS, Eisenbarth GS (1989) Testing the dual parameter model for predicting time to diabetes. Clin Res 37: 57 (Abstract)

8. Bosi E, Becker F, Bonifacio E et al. (1991) Progression to type 1 diabetes in autoimmune endocrine patients with islet cell antibodies. Diabetes 40: 977-984

9. Genovese S, Bonifacio E, McNally JM et al. (1992) Distinct cytoplasmic islet cell antibodies with different risks for type 1 (insulin-dependent) diabetes mellitus. Diabetologia 35:385388

10. Christie MR, Vohra G, Champagne P, Daneman D, Delovitch TL (1990) Distinct antibody specificities of a 64-kD islet cell antigen in type 1 diabetes as revealed by trypsin treatment. J Exp Med 172: 789-795

11. Christie MR, Hollands JA, Brwon TS, Michelsen BK, Delovitch TL (1993) Detection of pancreatic islet $64,000 \mathrm{M}_{r}$ auto- 
antigens in insulin-dependent diabetes distinct from glutamate decarboxylase. J Clin Invest 92: 240-248

12. Genovese S, Cassidy D, Bonifacio E, Bottazzo GF, Christie MR (1991) Antibodies to $37 / 40 \mathrm{kD}$ tryptic fragments of $64 \mathrm{kD}$ antigen are markers of rapid progression to type $1 \mathrm{in}$ sulin-dependent diabetes. Diabetes Res Clin Pract 14 [Suppl 1]:S11 (Abstract)

13. Bottazzo GF, Florin-Christensen A, Doniach D (1974) Islet cell antibodies in diabetes mellitus with autoimmune polyendocrine deficiency. Lancet II: 1279-1282

14. Bonifacio E, Lernmark $\AA$, Dawkins RL (1988) Serum exchange and use of dilution have improved precision of measurement of islet cell antibodies. J Immunol Methods 106: 83-88

15. Christie MR, Brown TJ, Cassidy D (1992) Binding of antibodies in sera from type 1 (insulin-dependent) diabetic patients to glutamate decarboxylase from rat tissues. Evidence for antigenic and non-antigenic forms of the enzyme. Diabetologia $35: 380-384$

16. Scherbaum WA, Mirakian R, Pujol-Borrell R, Dean BM, Bottazzo GF (1986) Immunocytochemistry in the study and diagnosis of organ-specific autoimmune diseases. In: Polak JM, Van Noorden S (eds) Immunocytochemistry - Modern methods and applications, 2 nd edn. Wright, Bristol, pp 456476

17. Vardi P, Crisa L, Jackson RA et al. (1991) Predictive value of intravenous glucose tolerance test insulin secretion less than or greater than the first percentile in islet cell antibody positive relatives of type 1 (insulin-dependent) diabetic patients. Diabetologia 34: 93-102

18. Bingley PJ, Colman PG, Eisenbarth GS et al. (1992) Standardization of IVGTT to predict IDDM. Diabetes Care 10: 1313-1316 